\title{
CIENCIA Y ÉTICA. EL MODELO DE LA CIENCIA MARTILLO
}

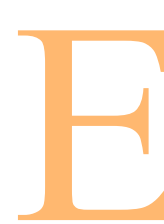

n cada ocasión en que se intenta discutir el vínculo entre la ciencia y la ética en la vida contemporánea, la antinomia entre «cientificismo» $\mathrm{y}$ «anticientificismo» suele ocupar la parte central de la escena, quedando planteada como un debate básico en la cual, sin embargo, no dejan de involucrarse otros referentes conceptuales que proceden tanto del campo de la filosofía, como del campo de la teoría social.

Los referentes filosóficos ocupan dos segmentos: el de la filosofía de la ciencia o epistemología, y el de las categorías filosóficas que se remontan, cuando menos, a la tradición del legado kantiano. Desde la apertura, en efecto, del dualismo entre razón teórica y razón práctica, no han cesado de examinarse distinciones subordinadas a ese dualismo como las que separan la lógica del ser de la lógica del deber, lo descriptivo de lo normativo, lo cognoscitivo de lo prescriptivo, la esfera del conocimiento de la esfera de la voluntad, el universo del sein del universo del sollen, la positividad de la captación de los valores, y otros del mismo tipo. En estos diferentes pares, la ciencia se ubica en la dimensión de lo teórico, y se asigna su relación con la ética al campo de lo práctico (lo normativo, el mundo del deber). La razón de esta distribución filosófica es que el nexo entre ciencia y ética concierne a la política científica.

La polémica entre cientifismo y anticientificismo suele estar fuertemente influida por argumentos que emanan de este dualismo filosófico $y$, también, del campo de la epistemología y la historia de la ciencia donde internalistas y externalistas asumen posiciones divergentes muchas veces frontales.

Así, mientras filósofos considerados como cientificistas se apoyan en el dualismo razón teórica/razón práctica -o en algunos de sus referidos modelos- y lo emplean para atrincherar la ciencia en el campo teórico y relegar todas las cuestiones vinculadas a su uso y aplicación a la exclusiva responsabilidad de 
las instancias públicas y privadas, los anticientificistas reniegan de todo dualismo pero, al hacerlo, se desinteresan de un cabal conocimiento de los problemas epistemológicos y conceptuales de la producción científica, para percibir del fenómeno científico sólo sus aristas negativas: destrucción de la naturaleza, mutilación de la vida, obstáculos al progreso de la moral y la virtud. En este sentido, siguen prisioneros del dualismo que rechazan.

De esta manera, las discusiones entre unos y otros contrincantes suelen comenzar haciendo inventarios con los resultados positivos o negativos respectivamente de la ciencia, para apoyar o mejorar sus fundamentos en un debate donde los contenidos emocionales ocupan el lugar ausente de un análisis racional que tome en cuenta tanto el sistema de elaboración de las teorías como el sistema social destinatario de esas teorías.

Sin embargo, cualquier inventario que distribuya por un lado los grandes beneficios traídos a la humanidad por la ciencia y, por otro, los efectos negativos y aún mortíferos de su aplicación por el poder estatal o corporativo privado, es una operación descriptiva completamente inútil e infértil para arrojar claves de inteligibilidad sobre la ciencia y la política científica en la vida contemporánea.

El sistema «balance y saldo» es impotente para elaborar una teoría que se proponga captar racionalmente la función de la ciencia en la sociedad de nuestros días, por cuanto este balance omite: a) visto el fenómeno de la ciencia desde la óptica del cientificismo, la fuerte masa de teoría social y no sólo epistemología que es necesaria para articular aquella teoría abrazadora del vínculo ciencia-ética; b) visto desde la óptica del anticientificismo, el conocimiento y la comprensión de la lógica y la metodología de la ciencia, y el conocimiento de una historia que se implanta en la modernidad como un efecto de la razón y de desencantamiento de un universo poblado de supersticiones e imágenes religiosas.

La óptica cientificista cree estar más cerca de la racionalidad en la medida en que se encuentra fuertemente entrenada en restringir el término racional exclusivamente a las teorías científicas, al método científico de las ciencias físico-naturales y a la historia interna intelectual de la ciencia, desinteresándose de la teoría social y de la historia externa de la ciencia considerada como mero complemento secundario de la primera.

Con el estrechamiento de lo racional a lo científico, y no pocas veces a lo científico-natural, la toma de posición cientificista se siente segura y en pleno derecho de considerar retrógrados y ultramontanos a los anticientificistas calificando así adecuadamente a buena parte de este universo integrado muchas veces por 
personas que, frente a los problemas que planta la ciencia, pretenden volver a modelos de sociedades bucólicas o arcádicas, o enfrentar sus efectos disvaliosos con propuestas de una contracultura, un conjunto de nostalgias religiosas o edificantes o una no menos utópica ciencia revolucionaria.

Sólo que en su condena, extienden desmesuradamente su radio, envolviendo en sus reproches a alternativas de examen del vínculo entre ciencias y ética que, lejos de ser reaccionarias no aceptan desvincular lo epistemológico de una teoría social que tome en cuenta la totalidad de la práctica científica, en un proceso de producción en que la ciencia como producto formado, como conjunto de teorías elaboradas es un simple momento abstracto no independiente ni indiferente de sus circuitos de circulación y consumo. Así el cientificismo que reprocha al anticientificismo la necesidad de saber de qué se habla -entendiendo por este saber una formación en ciencias físico-naturales y no una formación completa en alguna ciencia social- no comprende sus carencias en cuanto se trata de reconstruir el nexo entre ciencia y ética, y ciencia y sociedad por promover un formidable fenómeno de olvido y preterición de todos los elementos externos relacionados con la aplicación de esas mismas teorías.

De este modo si el anticientificismo falla en su captación del enlace teoría epistemológica/teoría social por desconocimiento de la primera teoría y el reemplazo de las bases de la segunda por una fuerte carga emotiva y moral, cuando no religiosa, desconsiderando el reemplazo del sistema de creencias premoderno por el post-contractual, el cientificismo falla por su limitado concepto de racionalidad, por la reducción de la primera teoría a los procedimientos lógico-metodológico de las ciencias naturales y por suponer que su motor de inferencias es suficiente para prescindir de toda teoría social a la que suele considerar como un mero conjunto de reflexiones generales, que no sabe de lo que hablar por estar empapada de filosofía social y moral más que de ciencia.

Sin embargo la racionalidad de la ciencia es coextensiva a la racionalidad de su aplicación en la sociedad.

Es dentro de este concepto no recortado de racionalidad que debe medirse el vínculo entre ética y ciencia y no como si la filosofía de la ciencia y la ética y política científica constituyesen dimensiones completamente independientes en que la primera se neutraliza frente a las segundas.

Lo que indica la teoría social es que de acuerdo con la política y la ética de la ciencia, el modo de producción de ésta, en tanto ese modo de producción tiene como excedente del producto formado 
su circulación y consumo, ésta varía sensiblemente. No sólo porque la ciencia es una práctica que en toda teoría incluye las condiciones de su aplicación, sino porque de acuerdo con las condiciones sociales, económicas, políticas y éticas de producción de la ciencia, los propios procedimientos lógico-metodológicos de que da cuenta la así llamada historia interna de la ciencia, se van articulando y variando.

El análisis, aislado de los materiales de inferencia lógica, el proceso de sistematización de las teorías, el modo de operatividad del instrumental matemático y su vinculación con el material empírico, sólo puede aceptarse como un momento abstracto de la epistemología, la que debe dar cuenta del fenómeno científico en la complejidad de sus relaciones. Epistemología de la ciencia no es lógica de la ciencia «tout court», como explícita o implícitamente se ha sostenido en muchos filósofos de tendencia anglosajona.

Ahora bien, una pregunta inherente al nexo entre la ciencia y la ética como la deliberada complicidad y silencio de algunos científicos creadores de teorías para el exterminio de los hombres, ha tratado de ser soslayada desde el campo del cientificismo, apelando a lo que se conoce como el modelo de la ciencia martillo.

Esta pregunta en efecto, ha sido contestada a veces echando mano de la distinción entre la ciencia y su uso. Una cosa, se arguye, es la ciencia como expresión del conocimiento y la racionalidad del hombre, y otra cosa es su uso o mal uso por instituciones, gobiernos y políticas. Los científicos no son responsables del uso que haga de sus teorías fuera de los laboratorios, el poder. Criterio que se desea abonar con este $\mathrm{u}$ otro ejemplo semejante: la ciencia es como un martillo que a veces se usa para clavar un clavo y otras veces para aplastar la cabeza de una persona.

Este criterio de demarcación entre la ciencia y su uso, digamos entre la buena ciencia y el mal uso, no es satisfactorio, ni apto para dilucidar el papel de la ciencia en la sociedad y la cultura del hombre según su evolución actual a fines de nuestro siglo, ni menos aún para un examen de la metodología de las teorías científicas.

La distinción entre «sanos» productos científicos y el uso «insano» de estos productos, fuera ya de las manos de los científicos, por los gobiernos, los estados, las agencias o corporaciones, no es una descripción ni siquiera aproximada de las modalidades que asume la producción científica en esta centuria.

El criterio de demarcación indicado silencia no sólo las 
peculiaridades del modo de producción de la ciencia y de la tecnología por el Estado militar-industrial, sino un universo, no precisamente secundario, de teorías que son en sí mismas mortíferas, es decir que emplean recursos lógicos-metodológicos combinados para producir la destrucción del hombre y la naturaleza. Son teorías mortíferas en sí, mala in se, que salen de la labor de científicos y técnicos amalgamados en laboratorios e instituciones. Teorías que, desde el inicio, se proyectan, planifican, y elaboran sin otro destino, ni más finalidad, que la destrucción del hombre y su entorno ecológico.

Tenemos un ejemplo aislado pero que podría multiplicarse: la producción de la bomba neutrónica.

¿Podemos hablar a su respecto de una teoría, la teoría sobre fisión del átomo, originariamente «neutral» usada luego en forma ominosa por el poder? ¿Se corresponde esto con la metáfora de una teoría martillo-para-clavar-un-clavo en un primer paso y, en un segundo, martillo-para-romper-el-cráneo-de-una-persona?, ¿estamos en presencia de una sola teoría con buen o mal uso alternativo y dependiente de la política o, por el contrario al producirse la bomba que destruye a los seres y deja intactas las cosas materiales como edificios, instalaciones, etc., se lo hace en base a nuevas teorías científicas que complementan y se agregan a la primitiva?

En el paso de lo neutral (por llamarlo de alguna manera) a la tecnología neutrónica, aparecen nuevas teorías científicas respecto de la originaria, nuevas observaciones, nuevas experiencias, nuevo instrumental lógico-matemático, nuevos procedimientos y nueva articulación que permiten al producto científico producir la muerte en cualquiera de las formas de su aplicación y no, por ejemplo, la energía eléctrica.

Del mismo modo, entre las teorías de los físicos sobre la energía nuclear y la producción de los distintos modelos de bombas atómicas hay un tramo de tecnología pero también un tramo de teorías científicas complementarias, con cambios en los procedimientos de metodología interna, sin los cuales el producto científico destructivo no sale al mercado de la muerte.

Se trata de teorías en cualquiera de los sentidos que pueda darse a la palabra, teorías científicas con hipótesis, con sistema de axiomas, con aparato semántico, términos teóricos y observacionales, que no pueden tener otro uso que el de martillo-rotura-de-cráneos.

¿Estarán los científicos, de contrato-a-buen-sueldo, autores de esas teorías (o sus colegas cientistas naturales que afirman dogmáticamente la neutralidad de la ciencia) en condiciones de 
únicos epistemológicos válidos para expedirse sobre ellas, o podrán y deberán expedirse también los epistemólogos que no son físicos aunque en su perfil predomine el interés sobre la historia externa de la ciencia?

La respuesta de los partidarios del modelo de ciencia-martillo corre así: el cientista natural se pondrá en una habitación el guardapolvos de metodólogo para expedirse sobre la bondad de los procedimientos inferenciales y empíricos puestos en juego en la elaboración de las teorías cuyas únicas condiciones de aplicación son la muerte de los hombres y la salvación de los edificios, pero pasará luego a otra habitación donde con nuevo guardapolvos se expedirá como hombre ético acerca de la función, el modo de producción, circulación y consumo del producto.

Esta concepción de las dos habitaciones del científico o del epistemólogo, correlato de la concepción de la ciencia-martillo de doble uso, no es satisfactoria, y emana de la vieja distinción entre ciencia pura-ciencia aplicada. En esta esquemática y simplista división de la ciencia (no obstante el peso que tiene en la tradición) la ciencia pura sería neutral y desprovista de toda connotación ética, política e ideología, en tanto que a la aplicación de la ciencia le correspondería asumir la condición de buen o mal uso.

La ciencia pura no es, sin embargo, una bonne à tout faire, ciencia lista para todo servicio.

Como lo han puesto en evidencia Gaston Bachelard, Louis Althusser siguiendo sus pasos, C. Ulises Moulines y todos los epistemólogos que defienden la non statement view (concepción no enunciativa de las teorías) las teorías incluyen sus condiciones de aplicación en su aparato conceptual. En cuanto a las teorías empíricas, Moulines al referirse al problema de los aspectos semánticos y pragmáticos de las ciencias y a la imposibilidad de separar la tarea de reconstruir teorías particulares de la tarea de aclarar la noción de aplicación, dice: «Pero no creo que esto sea metodológicamente aceptable. Las teorías empíricas están siempre construidas en vista a algunas aplicaciones «externas» concretas, de tal modo que las aplicaciones están incluidas también conceptualmente en la teoría misma. No podemos realmente separar las dos cosas. Algunos autores, que de algún modo se han dado cuenta de que las teorías y sus aplicaciones están entrelazadas conceptualmente, han propuesto la famosa tesis de la "carga teórica" de todas las observaciones empíricas. Pero parece que han olvidado señalar la otra cara de la moneda, a saber, lo que podríamos llamar la "carga aplicativa" de todos los constructos teóricos. 
Carnap y Hempel ya habían tratado de hacer justicia a este aspecto al introducir las llamadas "reglas de correspondencia" y los "postulados de significación". Sin embargo, su construcción de tales correspondencias es forzada y en parte ficticia. No puede decirse que proporcionan una solución verdaderamente satisfactoria, aunque se encontraban en la dirección correcta.

En los últimos años cierto número de filósofos de la ciencia se han ocupado del problema de proporcionar un concepto adecuado de teoría que incluya la noción de aplicación de un modo realista. Los enfoques de autores como Sneed, Stegmüller, Ludwig van Fraasen y el grupo polaco, aunque viviendo en tradiciones diferentes, todos tratan de proporcionar una solución adecuada al problema de la inclusión de las aplicaciones dentro de un concepto complejo de «teoría».

Efectivamente, Wolfgang Stegmüller, en Estructura y Dinámica de Teorías, se propone tomar muy en serio la idea de las diversas aplicaciones de una misma teoría, que constituye uno de los elementos claves de la concepción no enunciativa de las teorías. En el interior de las restricciones técnicas de esta concepción - de la que no nos ocuparemos aquí- su propósito es incluir una forma precisada de esta idea en el método de Ramsey (solución Ramsey al problema de los términos teóricos).

Desde luego, esto es una innovación a la idea de «la aplicación universal» de la teoría que dominó la mayoría de los análisis del concepto clásico de teoría en la filosofía de la ciencia. Muy probablemente, esta idea universalizadora de las teorías estuvo muy ligada a la mecánica clásica de partículas que da la impresión de ser aplicable a «todo». Stegmüller reproduce esta imagen intuitiva, así: «Dadas las trayectorias de todos los cuerpos materiales del universo para todo el tiempo, existen funciones de masa y fuerza que, si se añaden a las funciones de posición fijadas por esas trayectorias, proporcionan un modelo de una axiomatización adecuada de la mecánica clásica de partículas, en la medida en que ésta se complete con leyes dinámicas apropiadas. Así, pues, hay un solo dominio de aplicación de esta teoría, a saber, el cosmos en toda su extensión espacio-temporal».

Stegmüller hace un inventario de todas las razones que hablan en contra de este aspecto cósmico de la aplicación de teorías, propio del modelo estándar.

Aunque en forma más intuitiva, es decir no relacionada con el complejo examen de la estructura de teorías físicas a partir de Sneed, esta idea de la inclusión de las condiciones de aplicación de una teoría en el mismo tejido conceptual de ellas, estaba incluida en el desarrollo que Althusser propusiera de lo que llamó en Pour 
Marx, «la práctica teórica», como también en Gaston Bachelard referida al concepto.

Quizá valga la pena repetir uno de los párrafos con que aludí a ello en mi Neopositivismo e Ideología, contenido en el capítulo 14: «La errónea interpretación neopositivista se finca también en una notoria inadvertencia sobre los escritos de Althusser y Bachelard, en cuanto éstos consignan que la ciencia es un estatuto que incluyen en lo interior de su práctica sus mismas condiciones de aplicación. Así la división clásica entre teoría y aplicaciones de la teoría es rechazada, incorporando dicha práctica sus condiciones de aplicación. Condiciones de aplicación no son las efectividades tecnológicas sino las «condiciones» no formales y formales que la posibilitan. La práctica totaliza y actualiza así la historia misma del concepto. "En la experiencia -refiere Bachelard- busca las ocasiones para complicar el concepto, para realizar las condiciones de aplicación que la realidad no recusa. Es entonces cuando se advierte que la ciencia realiza sus objetos sin encontrarlos jamás hechos". Un concepto se torna así científico en el interior de su práctica teórica, en un proceso que incluye las propias técnicas de realización. Este proceso constructivo engloba nuevas pruebas experimentales que implican a su vez, deformar los conceptos primitivos, «estudiar las condiciones de aplicación de esos conceptos y, sobre todo, incorporar las condiciones de aplicación de un concepto en el sentido mismo del concepto... Un conocimiento es un conocimiento que se verifica progresivamente en cada una de sus adquisiciones. Si tuviéramos que esperar la referencia a lo real, base empírica y epílogo de escena, creeríamos que lo real estuvo ausente de toda la actividad previa y aparecería como forma expresiva postrera y epifánica, El élan científico se diluiría en tanteos carentes de una coordinación más o menos activa y no sabríamos distinguir lo arbitrario-convencional de lo natural, como si todo forjase una red endeble de hipótesis tan poco exigentes que escaparían al riesgo de ser desmentidas. Es el progreso paulatino de la práctica teórica el que determina las discriminaciones y propone hipótesis más finas en todo el curso del proceso y en un enlazado y coetáneo proceso de verificación que muchas veces le antecede -como dice Bachelard- o lo realimenta. No hay, pues, una cuestión de verificación de una totalidad blindada, por sí o por no, como se le asigna a un contexto télesis de las instancias procedimentales. Cada instancia, adjetiva, procesal, cada nivel, supone técnicas de validación, en la misma ruta de la construcción. La ciencia no se asemeja al procedimiento jurídico, donde cada etapa del proceso judicial se va cumpliendo sin prejuzgar y a la espera de una sentencia firme 
y definitiva que coronaría la litis. El juez científico se inmiscuye en cada uno de los tramos, dictamina de pleno derecho y no aguarda un bloque confirmatorio final»».

Si toda teoría incluye conceptualmente sus condiciones de aplicación, si toda teoría tiene un campo de aplicaciones propuestas, si el modelo cósmico de la aplicación de las teorías, es insatisfactorio, la imagen de la ciencia-martillo a doble uso pierde por completo todo significado. Los científicos autores de teorías cuyo campo de aplicación incluya dispositivos teóricos de resultados tecnológicos directamente criminoides, y es esto lo que ocurre en un universo de teorías muy vasto, carecen de todo margen para eludir su responsabilidad. Con respecto a ello, y a sus cómplices tecnocráticos, se potencia lo que Bertrand Russell había ya expresado en su clásico artículo «Las responsabilidades sociales de los científicos», de 1960, que reproduce la revista Ética y Ciencia $N^{\circ} 1$ de Buenos Aires: «En el mundo moderno es imposible para un hombre de ciencia, decir con cierta honestidad: "Mi tarea es proporcionar conocimiento, y el uso que se haga del conocimiento no es de mi responsabilidad"». 